\title{
Bio-optical footprints created by mesoscale eddies in the Sargasso Sea
}

\author{
D. A. Siegel, ${ }^{1}$ P. Peterson, ${ }^{1}$ D. J. McGillicuddy Jr., ${ }^{2}$ S. Maritorena, ${ }^{1}$ and N. B. Nelson ${ }^{1}$ \\ Received 4 April 2011; revised 27 May 2011; accepted 31 May 2011; published 14 July 2011.
}

[1] We investigate the bio-optical footprints made by mesoscale eddies in the Sargasso Sea and the processes that create them through an eddy-centric approach. Many $(>10,000)$ eddies are identified and followed in time using satellite altimetry observations and the spatial ocean color patterns surrounding each eddy are assessed. We find through a sequence of statistical hypothesis tests that not one but several mechanisms (i.e., eddy pumping, eddy advection and eddy-Ekman pumping) are responsible for the spatial-temporal ocean color patterns following individual eddies. Both eddy pumping and the eddy-Ekman pumping mechanisms alter subsurface nutrient distributions thereby driving biogeochemical cycles, while the eddy advection mechanism to first order stirs existing horizontal gradients in bio-optical properties. This work illustrates both the promise and some of the limitations of satellite observations for assessing the biogeochemical impacts of mesoscale eddies. Citation: Siegel, D. A., P. Peterson, D. J. McGillicuddy Jr., S. Maritorena, and N. B. Nelson (2011), Biooptical footprints created by mesoscale eddies in the Sargasso Sea, Geophys. Res. Lett., 38, L13608, doi:10.1029/2011GL047660.

\section{Introduction}

[2] Mesoscale eddies are ubiquitous features of the extra-tropical sea and play important roles in the global ocean heat budget and in the general circulation of the oceans [e.g., Robinson, 1983]. Satellite altimetry provides unique opportunities for identifying, tracking and quantifying the dynamics of these mesoscale features [e.g., Chelton et al., 2007, 2011]. Earlier work interpreted the westward propagating sea level anomaly (SLA) signals found using a single altimeter data set as Rossby waves [Chelton and Schlax, 1996]. It was not until four or more satellite altimeter data sets were merged that these propagating features were interpreted as mesoscale eddies [Pascual et al., 2006]. These distinctions are important since both midlatitude Rossby waves and mesoscale eddies propagate westward, only eddies transport water parcels as they move [e.g., McGillicuddy et al., 1998, 2007; Siegel, 2001; Chelton et al., 2007, 2011].

\footnotetext{
${ }^{1}$ Earth Research Institute, University of California, Santa Barbara, Santa Barbara, California, USA.

${ }^{2}$ Woods Hole Oceanographic Institution, Woods Hole, Massachusetts, USA.

Copyright 2011 by the American Geophysical Union. 0094-8276/11/2011GL047660
}

[3] Eddies also have important roles on ecological and biogeochemical processes through their contributions to vertical nutrient transport and alteration of the underwater light field [e.g., Falkowski et al., 1991; Klein and Lapeyre, 2009]. However, the underlying mechanism through which eddies affect ocean ecosystems remains hotly debated. From published reports in the literature, four dominant mechanisms can be synthesized (Figure 1): eddy pumping due to the vertical uplift of the upper thermocline inside the eddy [McGillicuddy et al., 1998; Siegel et al., 1999], eddy-Ekman pumping caused by spatial changes in wind stress due to eddy rotation [Martin and Richards, 2001; McGillicuddy et al., 2007], eddy advection of meridional property gradients around an eddy [Siegel et al., 2008; D. Chelton et al., The influence of nonlinear mesoscale eddies on oceanic chlorophyll, submitted to Science, 2011] and submesoscale pumping [Lévy et al., 2001; d'Ovidio et al., 2004; Calil and Richards, 2010]. Discrimination among these mechanisms is important because each will have a different impact on upper ocean biogeochemical processes.

[4] We hypothesize that the different eddy mechanisms will imprint specific spatial pattern in bio-optical properties, such as the chlorophyll concentration $(C h l)$, when viewed following an eddy (Figure 1). Eddy pumping should result in higher (lower) $\mathrm{Chl}$ values within the eddy center for a cyclone (anticyclone) while eddy advection will create an asymmetric pattern with respect to eddy rotation depending on the rotation rate and the meridional $C h l$ gradient. Increases in wind-forcing should cause a decrease (increase) in Chl inside a cyclone (anticyclone), creating $C h l$ anomalies that are opposite in sign to those produced by eddy pumping. Submesoscale upwelling will presumably create elevated $\mathrm{Chl}$ levels in the high velocity regions surrounding eddies of both signs (Figure 1).

[5] In the Sargasso Sea, both "regular" anticyclones and anticyclonic mode-water eddies are observed [e.g., McGillicuddy et al., 1999, 2007; Sweeney et al., 2003]. In the center of a mode-water eddy, its main thermocline is depressed providing its anticyclonic circulation but its seasonal thermocline is elevated toward the sea surface, creating a biological response similar to a cyclone. Mode-water eddies can be highly productive, particularly at the base of the nutricline [McGillicuddy et al., 1999, 2007].

[6] To quantify these processes, we take an eddy-centric point of view and assess the satellite ocean color patterns following individual eddies in the Sargasso Sea. We show consistency with many of the mechanisms listed above, but not all mechanisms are active at any given time. We discuss the implications of these results and provide directions for 

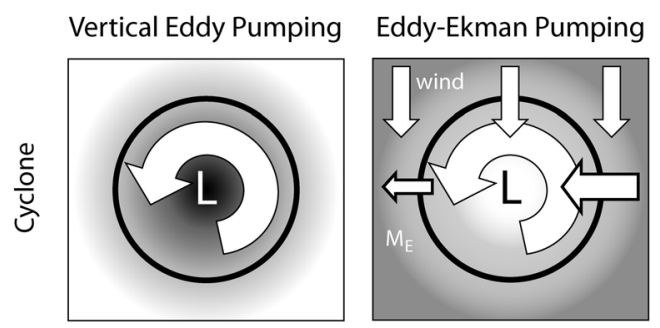

Eddy Advection
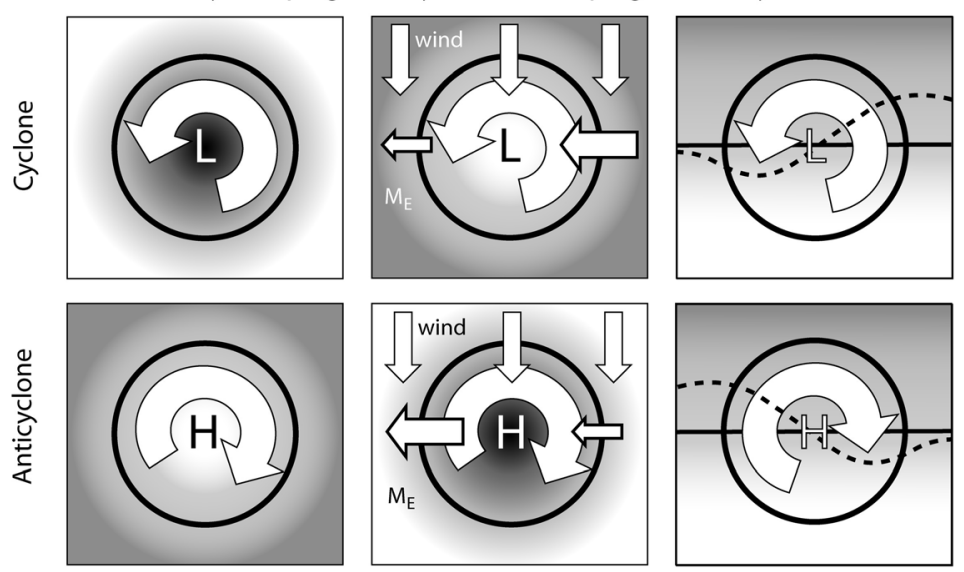

Submesoscale Pumping
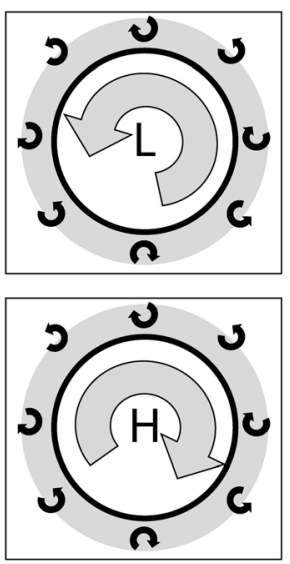

Figure 1. Illustration of four hypothesized mechanisms through which mesoscale eddies alter spatial patterns of bio-optical properties; (left) vertical eddy pumping, (middle-left) eddy-Ekman pumping, (middle-right) eddy advection, and (right) submesoscale pumping. (top) What is postulated for a cyclone (low sea level anomaly); (bottom) what should happen for an anticyclone (high sea level anomaly). The shading provides a depiction of the relative change in bio-optical properties hypothesized for each mechanism. The case for a mode-water eddy is anomalous as their upper-ocean isopycnal surfaces trend toward the sea surface within these features while the overall thermocline structure results in a high sea level anomaly and an anticyclonic circulation. See the text for further details.

future investigations of the biogeochemical impact of mesoscale eddies.

\section{Data and Methods}

\subsection{Sea Level Data Processing}

[7] Weekly merged altimetry fields of merged sea level anomaly $(S L A)$ at $1 / 4^{\circ}$ resolution from SSALT/DUACS [Pascual et al., 2006] were analyzed to identify and track eddies for a domain bounded by $20^{\circ}$ to $42^{\circ} \mathrm{N}$ (with the Gulf Stream masked out; Figure S1 of the auxiliary material). ${ }^{1}$ For each weekly map from June 2002 to July 2007, a second order polynomial surface was subtracted from the weekly $S L A$ to remove the effects of steric heating and large scale gradients from the identification of eddies. The resulting spatial anomalies were normalized by the long-term standard deviation spatial distribution and mesoscale features were identified where the absolute value of the normalized $S L A$ was $\geq 1.5$. Negative anomalies were characterized as cyclones and positive anomalies as anticyclones. The center location and size of each eddy were recorded and eddy trajectories were constructed automatically and each trajectory was evaluated manually. Figure S1 provides more information on the procedure and Figure S2 shows the eddy trajectories used in this analysis.

\subsection{Ocean Color Data Processing}

[8] Merged satellite ocean color observations from both the SeaWiFS and MODIS-Aqua missions were used to maximize available coverage [Maritorena et al., 2010] (http://wiki.icess.ucsb.edu/measures). Although the focus is on chlorophyll concentrations $(C h l)$, identical analyses were conducted for the absorption coefficient of colored dis-

\footnotetext{
${ }^{1}$ Auxiliary materials are available in the HTML. doi:10.1029/
} 2011 GL047660. solved and detrital materials $(C D M)$ and are included as a test of statistical robustness (see the auxiliary material). $C D M$ is likely a good index for mesoscale eddy activity because its subsurface maximum is shallower than the subsurface Chl maximum [Nelson et al., 2007].

[9] Daily, multisatellite merged, $9 \mathrm{~km}$ fields were logtransformed and interpolated onto a $1 / 4^{\circ}$ spatial - weekly (7 day) resolution grid for the period July 2002 to June 2007. Spatial anomalies, $\Delta C h l$, were determined by first calculating a moving $15 \times 15$ pixel $(375 \mathrm{~km}$ by $\sim 318 \mathrm{~km})$ spatial average of the $\ln (C h l)$ fields and subtracting these low-passed fields from the original $\ln (C h l)$ fields [Siegel et al., 2008].

\subsection{Eddy Footprints}

[10] Weekly ocean color fields were sampled in a $500 \mathrm{~km}$ by $500 \mathrm{~km}$ box centered on each eddy. Ocean color pixels within the eddy were designated using the results from the

Table 1. Statistics Over All Eddies With Ages $\geq 3$ Weeks

\begin{tabular}{|c|c|c|}
\hline $\begin{array}{c}\text { Mean (s.d.) Statistics Over All } \\
\text { Eddy Tracks }\end{array}$ & Cyclones & Anticyclones \\
\hline Number Eddies & 8093 & 6105 \\
\hline Number Eddy Trajectories & 620 & 477 \\
\hline Diameter $(\mathrm{km})$ & $134(43)$ & $131(45)$ \\
\hline Age (weeks) & $12(17)$ & $12(16)$ \\
\hline Distance traveled $(\mathrm{km})$ & $384(627)$ & $355(580)$ \\
\hline Translation speed $(\mathrm{km} / \mathrm{d})$ & $4.8(5.5)$ & $4.6(5.3)$ \\
\hline Sea level anomaly $(\mathrm{cm})$ & $-13.7(12.9)$ & $11.4(7.9)$ \\
\hline Wind Speed $(\mathrm{m} / \mathrm{s})$ & $7.4(1.6)$ & $7.2(1.3)$ \\
\hline$\partial C h l / \partial y\left(\log \left(\mathrm{mg} \mathrm{m}^{-3}\right) /{ }^{\circ}\right.$ Latitude $)$ & $0.048(0.094)$ & $0.041(0.095)$ \\
\hline Latitude $\left({ }^{\circ} \mathrm{N}\right)$ & $31.1(4.5)$ & $30.9(4.7)$ \\
\hline $\begin{array}{c}\text { Mean (95\% c.i.) Differences } \\
\text { in Mean Spatial Patterns in } \Delta C h l\end{array}$ & $\begin{array}{c}\text { Cyclones } \\
(\mathrm{N}=8093)\end{array}$ & $\begin{array}{l}\text { Anticyclones } \\
(\mathrm{N}=6105)\end{array}$ \\
\hline$\Delta C h l_{\text {In }}-\Delta C h l_{\text {Out }}$ & $\mathbf{0 . 0 1 3 1}(0.0059)$ & $-\mathbf{0 . 0 2 0 9}(0.0072)$ \\
\hline$\Delta C h l_{\text {East }}-\Delta C h l_{\text {West }}$ & $-\mathbf{0 . 0 2 6 9}(0.0073)$ & $\mathbf{0 . 0 2 3 7}(0.0045)$ \\
\hline
\end{tabular}




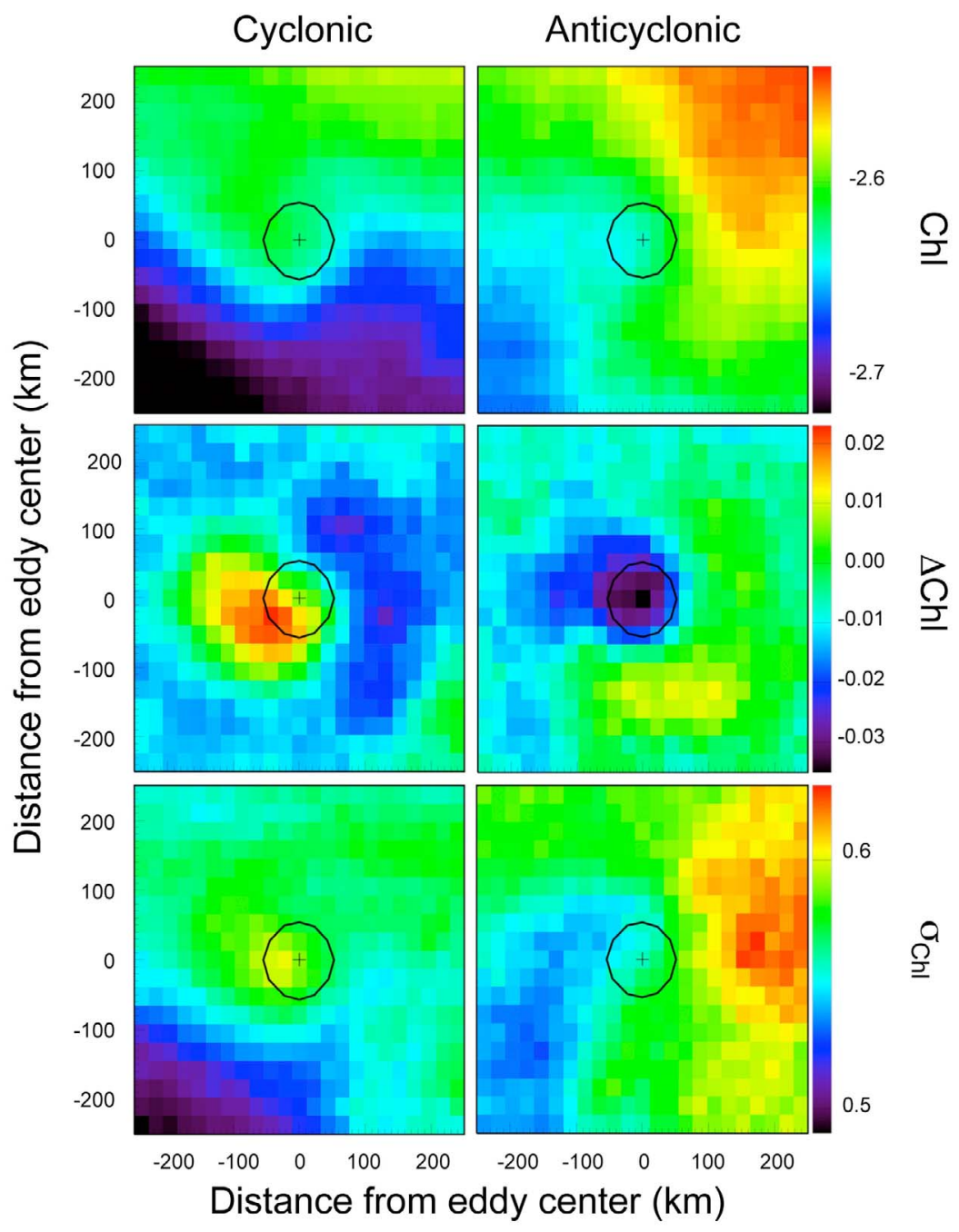

Figure 2. (top) Plan view depictions of log-transformed $C h l$ retrievals, (middle) the anomaly of log-transformed Chl anomaly $(\Delta C h l)$, and (bottom) the standard deviation of the log-transformed $C h l$ anomaly ( $\left.\sigma_{c h l}\right)$ for all (left) cyclonic and (right) anticyclonic eddies for eddies identified with trajectories longer than 3 weeks. Panels are $500 \mathrm{~km}$ on a side centered on the eddy center. The black circle is the trace of an average eddy size. A total of 8093 cyclonic and 6105 anticyclonic eddy-centric images were used to construct these plan view depictions.

normalized SLA analysis. Pixels outside of the eddy were selected quasi-randomly from the $500 \mathrm{~km}$ box matching the same number of pixels inside the eddy for consistency. A 4 pixel buffer region between the inside and outside pixels was employed where no outside pixels were selected. To assess asymmetry in the eddy signals, east and west eddy masks were calculated by shifting the inside eddy mask one eddy radius to the east and west, respectively. Various sampling schemes were tried and the choices above resulted in the best discriminations. Eddies tracked for $\geq 3$ weeks were considered for ensemble analyses while temporal changes along an individual eddy's trajectory were evaluated only for eddies followed for at least 15 weeks.

\subsection{Environmental Correlates}

[11] Eddy center $S L A, S L A_{\text {eddy }}$, was sampled as a measure of eddy strength. Wind speeds averaged over the $500 \mathrm{~km}$ eddy-following domain were provided from twice daily vector wind images from QuikSCAT [McGillicuddy et al.,
2007]. Last, meridional gradients for $\ln (C h l)$ were calculated over the entire $500 \mathrm{~km}$ box by linear regression.

\section{Results}

[12] We identified 8093 cyclonic and 6105 anticyclonic eddies that were followed for at least 3 weeks (Table 1). Eddy diameters were $\sim 130 \mathrm{~km}$ and westward propagation speeds were $\sim 4.7 \mathrm{~km}$ per day for both cyclones and anticyclones. The mean age for the ensemble of eddies tracked for three or more weeks was 12 weeks independent of type.

[13] The spatial mean distribution of chlorophyll $(\ln (C h l))$ and the chlorophyll concentration anomaly $(\Delta C h l)$ calculated over the ensemble of eddies followed for $\geq 3$ weeks is shown in Figure 2 (CDM patterns are shown in Figure S3). The mean $\ln (C h l)$ spatial patterns are very small with spatial variations less than $0.001 \mathrm{mg} \mathrm{m}^{-3}$ and are smaller than detection limits for field chlorophyll $a$ concentrations [e.g., Knap et al., 1996]. Despite this, the Chl pattern gives a 
Table 2. Regression Statistics for $\Delta C h l$ Differences Versus Environmental Parameters Over All Eddies ${ }^{\mathrm{a}}$

\begin{tabular}{|c|c|c|c|c|c|c|}
\hline & \multicolumn{6}{|c|}{ Correlation Over Tracks, $r$} \\
\hline & \multicolumn{2}{|c|}{ Versus $S L A_{e d d v}$} & \multicolumn{2}{|c|}{ Versus Wind Speed } & \multicolumn{2}{|c|}{ Versus Meridional Gradient } \\
\hline & $r$ & P-Value & $r$ & P-Value & $r$ & P-Value \\
\hline \multicolumn{7}{|c|}{$\Delta C h l_{\text {in }}-\Delta C h l_{\text {out }}$} \\
\hline Cyclones & -0.532 & 0 & 0.131 & 0.001 & 0.091 & 0.024 \\
\hline Anticyclones & -0.108 & 0.019 & -0.034 & 0.452 & -0.203 & $7.7 e-6$ \\
\hline \multicolumn{7}{|c|}{$\Delta C h l_{\text {East }}-\Delta C h l_{\text {West }}$} \\
\hline Cyclones & 0.102 & 0.011 & -0.075 & 0.061 & -0.478 & 0 \\
\hline Anticyclones & 0.328 & $1.9 \mathrm{e}-13$ & 0.223 & $8.3 e-7$ & 0.617 & 0 \\
\hline
\end{tabular}

${ }^{\mathrm{a} C}$ Correlations with $\mathrm{p}$-values less than 0.01 are bold faced $(\mathrm{N}=8093$ for cyclones and $\mathrm{N}=6105$ for anticyclones). Track ages $\geq 3$ weeks.

sense of rotation consistent with the sign of the features (counter-clockwise for cyclones and clockwise for anticyclones). This results in higher $\Delta C h l$ values to the west of the eddy center for the cyclone and to the east of center for the anticyclone consistent with the eddy advection hypothesis (Figure 1). Further, the ensemble mean $\Delta C h l$ signal is strongly reduced within anticyclonic eddies and an increase is apparent inside cyclonic eddies. This shows a rough consistency with the eddy pumping hypothesis, especially for anticyclones. These interpretations are also reflected in the $C D M$ distributions (Figure $\mathrm{S} 3$ ).

[14] The consistency of these interpretations can be tested statistically by evaluating whether the $\Delta C h l$ levels inside the eddy are significantly different than those outside or by evaluating the east-to-west difference in $\Delta C h l$ calculated over the ensemble of eddies observed. Mean values of these differences, along with $95 \%$ confidence intervals for whether the mean differences are significantly different from zero, are given in Table 1. Over the ensemble of eddies analyzed, mean values of $\Delta C h l_{I n}-\Delta C h l_{O u t}$ are significantly greater than zero for cyclones and are significantly less than zero for anticyclones supporting the eddy pumping interpretation. The east to west differences in $\Delta C h l$ are also consistent with the eddy advection hypothesis as the mean $\Delta C h l_{\text {East }}-\Delta C h l_{\text {West }}$ values are significantly less than zero for cyclones and are significantly positive for anticyclones (Table 1). Further, the magnitudes of the east-west differences are somewhat larger than the in-out differences, suggesting an important role for the eddy advection mechanism in setting mean spatial patterns.

[15] Statistical relationships between the bio-optical footprints and selected environmental parameters calculated over the ensemble of eddies provide additional information about regulating mechanisms. For example, the eddy pumping mechanism predicts that values of $\Delta C h l_{I n}-\Delta C h l_{\text {Out }}$ should decrease as the $S L A_{\text {eddy }}$ increases and the thermocline deepens for both cyclones and anticyclones. This is supported in the observed negative correlations, particularly for cyclones, found between $\Delta C h l_{I n}-\Delta C h l_{O u t}$ and $S L A_{\text {eddy }}$ calculated over the ensemble of eddies (Table 2; see also Table S2 for the $C D M$ results). The eddy-Ekman hypothesis suggests a negative correlation should be found between wind speed and $\Delta C h l_{I n}-\Delta C h l_{\text {Out }}$ for cyclones and a positive correlation for anticyclones (Figure 1). However, this expectation is not found with this test (Table 2). A potentially complicating factor is that the strength of the eddy-Ekman effect depends not only on the strength of the wind, but also on the magni- tude of eddy surface currents, which is not accounted for in this pair-wise correlation. Last, although a significant correlation is found between $\Delta C h l_{I n}-\Delta C h l_{O u t}$ and meridional gradients of $\ln (C h l)$ (Table 2), a significant correlation is not found using $C D M$ (Table S2); suggesting that this relationship is not robust. These results support the importance of the eddy pumping mechanism for cyclones (and to a lesser degree for anticyclones) and do not support the role of the eddyEkman mechanism for setting mean conditions.

[16] A strong correlation is found between $\Delta \mathrm{Chl}_{\text {East }}{ }^{-}$ $\Delta C h l_{\text {West }}$ and the meridional gradient in $\ln (\mathrm{Chl})$ calculated over the ensemble of eddies (Table 2). The correlations are negative for cyclones $\left(\Delta C h l_{\text {East }}<\Delta C h l_{\text {West }}\right.$ in a counter-clockwise circulation) and positive for anticyclones $\left(\Delta C h l_{\text {East }}>\Delta C h l_{\text {West }}\right.$ in a clockwise circulation) as expected (Figure 1). For anticyclones, a strong correlation is also found between $S L A_{\text {eddy }}$ and $\Delta C h l_{\text {East }}-\Delta C h l_{\text {West }}$ consistent with increased rotation speed and increased advection of the mean Chl gradient (Table 2). However, a similar correspondence is not found for cyclones. These results both show that eddy advection becomes more important as the meridional gradient increases and to a lesser degree as the eddy strength increases.

[17] The statistical evaluations presented above show correspondence with several of the mechanisms presented in Figure 1 when assessed over the ensemble of eddies observed. Transient changes in bio-optical parameters are also expected following an individual eddy as it evolves in time and responds to changes in environmental conditions [Sweeney et al., 2003; Siegel et al., 2008]. Here, we assess the response of eddy bio-optical signals to changes in environmental conditions following the trajectories of individual eddies. For sampling reasons, we restrict our attention to eddies that were followed for 15 or more weeks ( 145 cyclonic and 104 anticyclonic trajectories in total). As described previously, the eddy pumping mechanism suggests that values of $\Delta C h l_{I n}-\Delta C h l_{\text {Out }}$ should increase as $S L A_{\text {eddy }}$ decreases regardless of the sign of the eddy. However, correlation coefficients between $\Delta C h l_{I n}-\Delta C h l_{O u t}$ and $S L A_{\text {eddy }}$ calculated over individual eddy trajectories vary dramatically and both strongly positive and strongly negative correlation coefficients are found (Figure S4). Averaging over the ensemble of eddy trajectories, we find that the mean correlation coefficient is significantly different from zero for anticyclones but not for cyclones (Table 3). The sign for the relationship indicates that $C h l$ anomalies inside an anticyclone decrease as $S L A_{\text {eddy }}$ increases supporting the eddy 
Table 3. Ensemble Mean Correlations Between $\Delta C h l$ and Environmental Parameters Over All Eddy Trajectories ${ }^{\mathrm{a}}$

\begin{tabular}{|c|c|c|c|c|c|c|}
\hline & \multicolumn{6}{|c|}{ Ensemble Mean Alongtrack Correlations, $r$} \\
\hline & \multicolumn{2}{|c|}{ Versus $S L A_{e d d y}$} & \multicolumn{2}{|c|}{ Versus Wind Speed } & \multicolumn{2}{|c|}{ Versus Meridional Gradien } \\
\hline & Mean & $95 \%$ c.i. & Mean & $95 \%$ c.i. & Mean & $95 \%$ c.i \\
\hline \multicolumn{7}{|c|}{$\Delta C h l_{\text {in }}-\Delta C h l_{\text {out }}$} \\
\hline Cyclones & -0.0068 & 0.0528 & -0.1096 & 0.0405 & -0.0844 & 0.0566 \\
\hline Anticyclones & -0.0825 & 0.0602 & 0.0663 & 0.0523 & 0.0512 & 0.0651 \\
\hline \multicolumn{7}{|c|}{$\Delta C h l_{\text {East }}-\Delta C h l_{\text {West }}$} \\
\hline $\begin{array}{l}\text { Cyclones } \\
\text { Anticyclones }\end{array}$ & -0.0241 & 0.0638 & -0.0611 & $\begin{array}{l}0.0002 \\
0.0530\end{array}$ & 0.1660 & 0.0704 \\
\hline
\end{tabular}

${ }^{a}$ Only tracks w/ages $\geq 15$ weeks are considered. Ensemble mean correlation estimates that are significantly different from zero ( $95 \%$ c.i.) are shown in boldfaced font ( $\mathrm{N}=145$ for cyclones and $\mathrm{N}=104$ for anticyclones).

pumping hypothesis. However, a corresponding significant correlation is not found for $C D M$ (Table S2).

[18] The expectation of the eddy-Ekman mechanism is that values of $\Delta C h l_{I n}-\Delta C h l_{\text {Out }}$ should increase in an anticyclone and decrease in a cyclone as the wind speed increases [e.g., McGillicuddy et al., 2007]. As found previously, the alongtrack correlation coefficients vary dramatically over the ensemble of available trajectories, although the distributions are now noticeably skewed (Figure S4). The mean correlation coefficients show a significantly negative value for cyclones and significantly positive one for anticyclones (Table 3). Over the ensemble of eddy trajectories, increased wind speeds increase $\Delta C h l$ signals inside anticyclonic eddies and decrease them in cyclones. A similar correspondence is found for $C D M$ (Table S2). This provides important evidence for the role of the eddy-Ekman pumping mechanism for regulating transient changes in an eddy's bio-optical signals.

[19] The eddy advection mechanism can also be tested by evaluating how alongtrack values of $\Delta C h l_{\text {East }}-\Delta C h l_{\text {West }}$ change in response to changes in the meridional gradient in $\ln (C h l)$ and $S L A_{\text {eddy }}$ (Table 3 ). Over the ensemble of trajectories, values of $\Delta C h l_{\text {East }}-\Delta C h l_{\text {West }}$ are significantly and strongly correlated with the meridional $\ln (C h l)$ gradient with appropriate signs for the eddy advection hypothesis. Significant correlations are not found with $S L A_{e d d y}$ suggesting that changes in rotation rate are second order to the strength of the meridional gradient in transient changes in the asymmetric bio-optical patterns for open ocean eddies.

\section{Discussion and Conclusions}

[20] The eddy-centric analysis of bio-optical footprints following individual eddies shows broad consistency with several hypothesized mechanisms. Although eddy-driven processes do drive synoptic variations in bio-optical properties, mean bio-optical spatial signals calculate over the ensemble of eddies observed are weak - smaller than can be assessed using standard field analysis protocols. However, by averaging over many eddies and eddy trajectories, consistency between the ocean color signals and several of the hypothesized mechanisms describing this bio-physical coupling can be uncovered. In particular, we find consistency with the eddy advection mechanism in nearly all of the evidence presented. In addition, consistency with both the eddy pumping and eddy-Ekman mechanisms could be diagnosed from several tests demonstrating that no single mechanism controls the bio-optical footprints created by mesoscale eddies.
[21] The one proposed mechanism in Figure 1 that has not been addressed yet is submesoscale eddy pumping. The expectation is that submesoscale upwelling motions will lead to elevated $C h l$ levels in the high velocity regions surrounding an eddy of either sign. We attempt to assess submesoscale upwelling by quantifying the mean spatial patterns in $\Delta C h l$ as well as its standard deviation, $\sigma_{C h l}$, sampled over the ensemble of eddies (Figure 2). For eddies of both signs, overall signal levels for $\sigma_{C h l}$ are higher than mean $\ln (C h l)$ patterns and a rough east to west decrease in $\sigma_{C h l}$ is found. However, there are no obvious signals in $\Delta C h l$ or $\sigma_{C h l}$ found at the periphery of eddies that would support a role for submesoscale processes locked onto an eddy's footprint. This lack of spatial correspondence makes sense considering the highly dynamic, turbulent nature of submesoscale motions [e.g., d'Ovidio et al., 2004]. This test of the role of submesoscale physics is likely too simple to provide a clear verdict and a thorough test linking field and satellite observations with appropriate numerical models is required.

[22] The tests of the eddy pumping hypothesis resulted in conflicting findings comparing anticyclones and cyclones. The ensemble mean $\Delta C h l$ patterns (Figure 2) show better correspondence with anticyclones than cyclones (also the statistics in Table 1), yet the correlation coefficient calculated between $\Delta C h l_{I n}-\Delta C h l_{O u t}$ and $S L A_{e d d y}$ signals over the ensemble of eddies is significant for cyclones but not for anticyclones (Table 2). This lack of symmetry may be caused by the presence of mode-water eddies which have an anticyclonic circulation but a biological response similar to a cyclone. Exploring the influence of these motions is beyond the scope of the present contribution as new methods must be developed to differentiate mode water eddies from "regular" anticyclones using sea surface temperature data. It also is possible that the eddy advection mechanism could have an imprint on the $\Delta C h l_{I n}-\Delta C h l_{\text {Out }}$ diagnostic. Chelton et al. (submitted manuscript, 2011) demonstrate that $C h l$ anomalies induced by eddy-driven advection are more pronounced on the leading edge of the eddy than the trailing edge. For westward-propagating eddies in a mean gradient with higher $C h l$ to the north, cyclones (anticyclones) would entrain more (less) high $C h l$ water from the north than low $C h l$ water from the south, resulting in a net increase in $C h l$ in its interior. Thus, the observed differences in $\Delta C h l_{I n}-\Delta C h l_{\text {Out }}$ may not be unequivocally attributable to eddy pumping.

[23] Last, the biogeochemical impact of the satelliteobserved bio-optical footprints needs to be addressed. The 
statistical results show overall consistency with the eddy advection mechanism. However, eddy advection will only advect water masses around the eddy and, to first order, should have little biogeochemical impact [Siegel et al., 2008]. Two other mechanisms, eddy and eddy-Ekman pumping, are directly involved with the vertical lifting of nutrient rich waters into the euphotic zone and therefore perform biogeochemical work. These changes can be seen from satellite but are likely more important at the base of the euphotic zone [McGillicuddy et al., 2007] and points to some of the limitations of satellite observations for assessing biogeochemical processes in the sea. To understand and quantify the biogeochemical impacts of eddy footprints and the contributing processes, integrated satellite and field observations coupled to numerical model simulations are required. In particular, new observation tools, such as oceanographic gliders and profiling floats instrumented with bio-optical sensors [Schofield et al., 2007; Boss et al., 2008], will provide new ways of assessing the subsurface processes that are critical for understanding and quantifying the impacts of the bio-optical footprints made by mesoscale eddies.

[24] Acknowledgments. We would like to acknowledge the support of the National Science Foundation and NASA. Discussions with Dudley Chelton and Ken Buesseler were helpful.

[25] The Editor thanks two anonymous reviewers for their assistance in evaluating this paper.

\section{References}

Boss, E., D. Swift, L. Taylor, P. Brickley, R. Zaneveld, S. Riser, M. J Perry, and P. G. Strutton (2008), Observations of pigment and particle distributions in the western North Atlantic from an autonomous float and ocean color satellite, Limnol. Oceanogr., 53, 2112-2122, doi:10.4319/lo.2008.53.5 part 2.2112.

Calil, P. H. R., and K. J. Richards (2010), Transient upwelling hot spots in the oligotrophic North Pacific, J. Geophys. Res., 115, C02003, doi:10.1029/2009JC005360.

Chelton, D. B., and M. G. Schlax (1996), Global observations of oceanic Rossby waves, Science, 272, 234-238, doi:10.1126/science.272. 5259.234 .

Chelton, D. B., M. G. Schlax, R. M. Samelson, and R. A. de Szoeke (2007), Global observations of large ocean eddies, Geophys. Res. Lett., 34, L15606, doi:10.1029/2007GL030812.

Chelton, D. B., M. G. Schlax, and R. M. Samelson (2011), Global observations of nonlinear mesoscale eddies, Prog. Oceanogr., doi:10.1016/j. pocean.2011.01.002, in press.

d'Ovidio, F., V. Fernandez, E. Hernandez-Garcia, and C. Lopez (2004), Mixing structures in the Mediterranean Sea from finite-size Lyapunov exponents, Geophys. Res. Lett., 31, L17203, doi:10.1029/ 2004GL020328.

Falkowski, P. G., D. Ziemann, Z. Kolber, and P. K. Bienfang (1991), Role of eddy pumping in enhancing primary production, Nature, 352, 55-58, doi: $10.1038 / 352055 \mathrm{a} 0$.
Klein, P., and G. Lapeyre (2009), The oceanic vertical pump induced by mesoscale and submesoscale turbulence, Annu. Rev. Mar. Sci., I, 351-375, doi:10.1146/annurev.marine.010908.163704.

Knap, A., A. Michaels, A. Close, H. Ducklow, and A. Dickson (Eds.) (1996), Protocols for the Joint Global Ocean Flux studies (JGOFS) core measurements, Rep. 19, U.N. Educ. Sci. Cult. Org., Paris. (Available at http://ijgofs.whoi.edu/Publications/Report_Series/reports.html\#No.19.)

Lévy, M., P. Klein, and A.-M. Treguier (2001), Impact of sub-mesoscale physics on production and subduction of phytoplankton in an oligotrophic regime, J. Mar. Res., 59, 535-565, doi:10.1357/002224001762842181.

Maritorena, S., O. H. Fanton d'Andon, A. Mangin, and D. A. Siegel (2010), Merged satellite ocean color data products using a bio-optical model: Characteristics, benefits and issues, Remote Sens. Environ., 114, 1791-1804, doi:10.1016/j.rse.2010.04.002.

Martin, A. P., and K. J. Richards (2001), Mechanisms for vertical nutrient transport within a North Atlantic mesoscale eddy, Deep Sea Res., Part II, 48, 757-773, doi:10.1016/S0967-0645(00)00096-5.

McGillicuddy, D. J., Jr., A. R. Robinson, D. A. Siegel, H. W. Jannasch, R. Johnson, T. D. Dickey, J. McNeil, A. F. Michaels, and A. H. Knap (1998), Influence of mesoscale eddies on new production in the Sargasso Sea, Nature, 394, 263-266, doi:10.1038/28367.

McGillicuddy, D. J., Jr., R. J. Johnson, D. A. Siegel, A. F. Michaels, N. Bates, and A. H. Knap (1999), Mesoscale variability of ocean biogeochemistry in the Sargasso Sea, J. Geophys. Res., 104, 13,381-13,394, doi:10.1029/1999JC900021.

McGillicuddy, D. J., Jr., et al. (2007), Eddy/wind interactions stimulate extraordinary mid-ocean plankton blooms, Science, 316, 1021-1026, doi:10.1126/science. 1136256.

Nelson, N. B., D. A. Siegel, C. A. Carlson, C. Swan, W. M. Smethie Jr., and S. Khatiwala (2007), Hydrography of chromophoric dissolved organic matter in the North Atlantic, Deep Sea Res., Part I, 54, 710-731, doi:10.1016/j.dsr.2007.02.006.

Pascual, A., Y. Faugere, G. Larnicol, and P.-Y. Le Traon (2006), Improved description of the ocean mesoscale variability by combining four satellite altimeters, Geophys. Res. Lett., 33, L02611, doi:10.1029/ 2005GL024633.

Robinson, A. R. (1983), Eddies in Marine Science, 609 pp., Springer, New York.

Schofield, O., et al. (2007), Slocum gliders: Robust and ready, J. Field Robotics, 24, 1-14. doi:10:1009/rob.20200.

Siegel, D. A. (2001), Oceanography: The Rossby rototiller, Nature, 409, 576-577, doi:10.1038/35054659.

Siegel, D. A., E. Fields, and D. J. McGillicuddy Jr. (1999), Mesoscale motions, satellite altimetry and new production in the Sargasso Sea, J. Geophys. Res., 104, 13,359-13,379, doi:10.1029/1999JC900051.

Siegel, D. A., D. B. Court, D. W. Menzies, P. Peterson, S. Maritorena, and N. B. Nelson (2008), Satellite and in situ observations of the bio-optical signatures of two mesoscale eddies in the Sargasso Sea, Deep Sea Res., Part II, 55, 1218-1230, doi:10.1016/j.dsr2.2008.01.012.

Sweeney, E. N., D. J. McGillicuddy, and K. O. Buesseler (2003), Biogeochemical impacts due to mesoscale eddy activity in the Sargasso Sea as measured at the Bermuda Atlantic Time Series (BATS) site, Deep Sea Res., Part II, 50, 3017-3039, doi:10.1016/j.dsr2.2003.07.008.

S. Maritorena, N. B. Nelson, P. Peterson, and D. A. Siegel, Earth Research Institute, University of California, Santa Barbara, Santa Barbara, CA 93106 , USA.

D. J. McGillicuddy Jr., Woods Hole Oceanographic Institution, Woods Hole, MA 02543, USA. 